\title{
INFLUÊNCIA DO FENÔMENO ENOS NOS PERFIS TEMPORAIS DE NDVI DAS ÁREAS ORIZÍCOLAS DO RIO GRANDE DO SUL
}

\author{
Eliana V. Klering ${ }^{1}$, Denise C. Fontana ${ }^{1,2}$, Rita M. Alves ${ }^{1}$, \\ Moacir Berlato ${ }^{2}$ \\ ${ }^{1}$ Centro Estadual de Pesquisas em Sensoriamento Remoto e Meteorologia (CEPSRM), Universidade Federal do \\ Rio Grande do Sul (UFRGS), eliana.klering@ufrgs.br \\ ${ }^{2}$ Faculdade de Agronomia, UFRGS
}

\section{RESUMO}

O objetivo deste trabalho foi investigar as relações entre os perfis temporais de NDVI das áreas cultivadas com arroz irrigado no Rio Grande do Sul e a variabilidade climática associada à ocorrência de eventos ENOS (El Niño Oscilação Sul). Foram utilizadas imagens de NDVI/MODIS e estatísticas oficiais de área cultivada e rendimento de grãos de arroz irrigado. Para tanto foram consideradas duas safras de ocorrência de La Niña, quatro de ocorrência de El Niño e quatro consideradas neutras. Os resultados mostraram que existem diferenças entre os perfis temporais representativos de safras de ocorrência de El Niño e La Niña, provavelmente associadas às condições meteorológicas características de ENOS. Assim, estes perfis podem ser utilizados como indicativo da variabilidade climática interanual.

\begin{abstract}
The objective of this work was to investigate the relationships between temporal profiles of NDVI of the rice crop areas in Rio Grande do Sul, State, and climate variability while the occurrence of ENSO events (El Niño Southern Oscillation). The data set were composed by NDVI/MODIS images and data of official agricultural statistics about the crop area and irrigated rice grain yield. Were considered two crop years of occurrence of La Niña, four of occurrence of El Niño and four considered neutral. The results showed that exist differences between the temporal representative profiles of harvests with occurrence of El Niño and La Niña, probably due to weather characteristics of ENSO. Thus, these profiles can be used as an indicator of interannual climate variability.
\end{abstract}

\section{INTRODUÇÃO}

O Rio Grande do Sul (RS) é considerado estabilizador da safra nacional de arroz, tendo sido responsável, na safra 2012/13, por 67,5\% da produção brasileira deste cereal. O Estado apresenta um incremento médio anual na produção do grão, entretanto, verifica-se grande variabilidade interanual do rendimento de grãos da cultura, o que é determinado pelos fatores de risco inerentes à atividade agrícola: mercado e adversidades climáticas. Quanto a este último, parte da variabilidade interanual dos rendimentos da cultura está relacionada com o fenômeno El Niño Oscilação Sul (ENOS), conforme o demonstrado por CARMONA \& BERLATO (2002). Entre os sensores orbitais disponíveis para o monitoramento dos cultivos destaca-se o MODIS/Terra, devido sua alta resolução temporal e moderada resolução espacial. Dos produtos resultantes deste sensor ressalta-se, como um dos mais utilizados para este fim, o Índice de Vegetação por Diferença Normalizada (NDVI). Os perfis temporais de NDVI, gerados a partir de observações sequenciais deste índice, indicam a evolução temporal de biomassa verde de um dossel agrícola permitindo o monitoramento do 
desenvolvimento e a detecção de anomalias de crescimento ao longo das safras (DEPPE et $a l ., 2007)$. Dentro deste contexto, o objetivo deste trabalho foi investigar as relações entre os perfis temporais de NDVI/MODIS, das áreas cultivadas com arroz irrigado no RS, e a variabilidade climática associada à ocorrência de eventos ENOS.

\section{MATERIAL E MÉTODOS}

A área de estudo deste trabalho compreendeu a região orizícola do RS, situada na metade sul do Estado (Figura 1). O período de estudo compreendeu 2 safras de ocorrência de La Niña (2000/01 e 2007/08), 4 safras de ocorrência de El Niño (2002/03, 2004/05, 2006/07 e 2009/10) e 4 safras neutras (2001/02, 2003/04, 2005/06, 2008/09) (NOAA, 2012). Para as análises, utilizaram-se dados oficiais de área cultivada e rendimento de arroz irrigado, obtidos do Levantamento Sistemático da Produção Agrícola do Instituto Brasileiro de Geografia e Estatística. Utilizaram-se, também, imagens provenientes do produto MODIS MOD13Q1, coleção 5, que contém composições de imagens de 16 dias de NDVI, com resolução espacial de 250 metros.

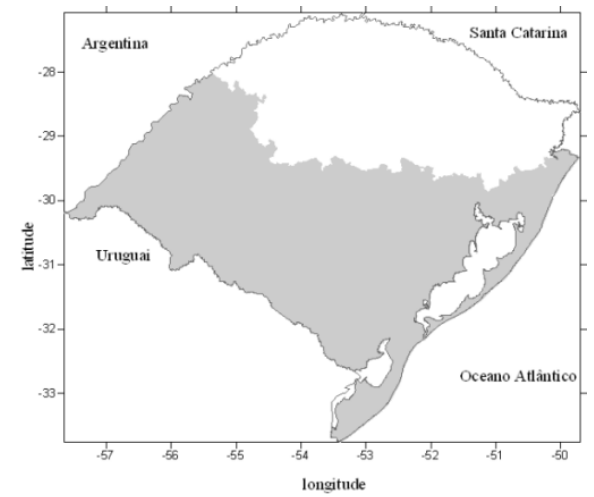

Figura 1. Região orizícola do RS.

Para a construção das máscaras de cultivo, utilizou-se uma metodologia baseada no comportamento espectro-temporal da cultura do arroz irrigado conforme o exposto em KLERING (2012). Após a definição das máscaras de cultivo, foram extraídos os perfis temporais de NDVI das áreas cultivadas com arroz, considerando as safras de ocorrência de ENOS e as safras consideradas neutras. A partir dos perfis temporais médios das safras de ocorrência do fenômeno foram discutidos aspectos relacionados ao calendário agrícola e ao rendimento de grãos da cultura.

\section{RESULTADOS E DISCUSSÃO}

Através da análise dos perfis temporais médios de NDVI/MODIS, das áreas cultivadas com arroz irrigado na região orizícola, apresentados na Figura 2, observa-se que para as safras de La Niña, o NDVI médio apresentou o valor mínimo com defasagem de uma quinzena com relação às safras consideradas neutras e duas com relação às safras consideradas como El Niño. Esclarecer estas diferenças é complexo, entretanto, parte deste entendimento se baseia no fato de que na primavera do ano de início de La Niña, em consequência da menor nebulosidade associada à diminuição de precipitação pluvial, tem-se um maior resfriamento do solo em função da maior perda de radiação de onda longa durante a noite. Assim, em safras de ocorrência de La Niña na metade sul do RS, o preparo do solo para semeadura normalmente é concluído antes do período recomendado como preferencial em virtude do 
maior número de dias sem precipitação. O máximo valor de NDVI, ocorrido no perfil médio de La Nina, e, também, com defasem de uma quinzena com relação aos ocorridos nas safras consideradas neutras e de ocorrência de El Niño. Este fato já era esperado, pois maiores valores de NDVI estão associados a maiores acúmulos de biomassa verde e, consequentemente, maiores rendimento de grãos. Embora as condições meteorológicas não tenham sido usadas diretamente na associação apresentada neste trabalho, é importante ressaltar que as condições distintas ocorridas em anos de ENOS têm uma importante relação com o rendimento final de grãos de arroz irrigado. Em safras caracterizadas por El Niño foram observados rendimentos de grãos inferiores à média ou muito próximos desta. Já nas safras de ocorrência de La Niña foi observado comportamento oposto.

\section{CONCLUSÕES}

Pode-se concluir que existem diferenças entre os perfis temporais representativos de safras de ocorrência de El Niño e La Niña, provavelmente associadas às condições meteorológicas características de ENOS, e, assim estes perfis podem ser utilizados como indicativo da variabilidade climática interanual na região de estudo.

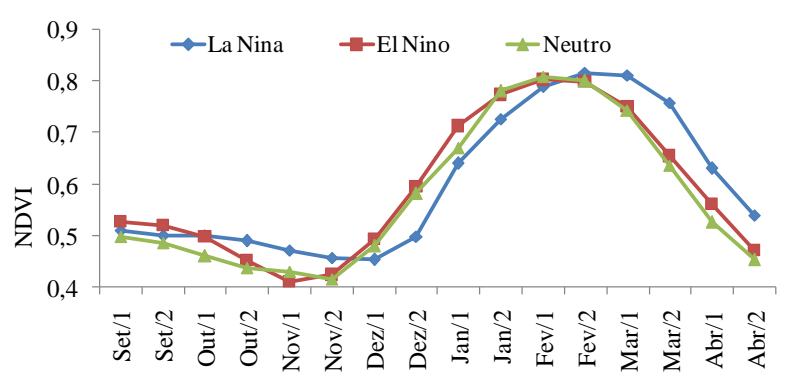

Figura 2. Perfis temporais médios de NDVI/MODIS, das áreas cultivadas com arroz irrigado, das safras de ocorrência de La Niña e El Niño e consideradas neutras, no RS.

\section{REFERÊNCIAS}

CARMONA, L.; BERLATO, M. El Niño e La Niña e o rendimento de grãos de arroz irrigado no Estado do Rio Grande do Sul. Revista Brasileira de Agrometeorologia, Santa Maria, v.10, n.1, p.147-152. 2002.

DEPPE, F. et al. Monitoramento da evolução temporal de cultivos agrícolas através de imagens TERRA/MODIS. In: SIMPÓSIO BRASILEIRO DE SENSORIAMENTO REMOTO, 13., 2007, Florianópolis. Anais... São José dos Campos: INPE, 2007. p. 145-152. KLERING, E. V. Mapeamento da área cultivada e estimativa de rendimento de grãos de arroz irrigado a partir de modelos agrometeorológicos-espectrais para o Rio Grande do Sul. 2012. 161f. Tese - PPG-Fitotecnia, UFRGS, Porto Alegre, 2012.

NOAA - National Oceanic and Atmospheric Administration. El Niño/Southern Oscillation (ENSO). Disponível em: <http://www.esrl.noaa.gov/psd/enso/>. Acesso em: 31 mar. 2012. 